\title{
Cosmo-política por un planeta durable Aprender a bien vivir en la Casa Común
}

\author{
Edgar Montiel ${ }^{1}$ \\ edgarmontiel2014@gmail.com
}

\begin{abstract}
A Horacio Cerutti, entrañable amigo, unidos siempre por los pensares y quehaceres de Nuestra América de la era planetaria.
\end{abstract}

\section{Comer mañana}

Para dar de comer a 8 mil millones de personas en el 2030 el planeta necesitará aumentar su producción anual de carne vacuna de 14 a 39 millones de toneladas, casi triplicarse. Y elevar las de carnero de 4 a 11 millones de toneladas. Las de cerdo subir de 21 a 56 millones de toneladas, más de dos veces y medio. Y respecto a pollos y huevos, tendrá que aumentar la producción de 22 a 82 millones de toneladas pollos, es decir casi cuatro veces más; y los huevos aumentar de 14 a 38 millones de tonelada por año. ${ }^{2}$

Este ritmo ciego de producción llevaría a profundizar un modelo ecocida, con consecuencias irreversibles para el planeta, pues aumentaría el recalentamiento climático: producir carne tiene el mayor efecto invernadero en la biósfera, un impacto traumático en el precario equilibrio del ecosistema planetario. ¿Qué dice el Informe Mundial del Planeta 2014?, que elaboró el Indicador Planeta Viviente para medir los cambios producidos en base a una muestra representativa de $10 \mathrm{mil}$ poblaciones de 5 especies claves: mamíferos, pájaros, reptiles, anfibios y pescados. Los resultados revelan una rotunda caída de $52 \%$ de estas especies, comparado a $1970^{3}$. Esto es el indicador de un colapso, que en 44 años la masa viviente (biomasa) de estas especies se contrajeran a menos de la mitad.

1 Filósofo y economista, Jefe de Políticas Culturales de UNESCO, París 2001-2009. Director del libro Pensar un mundo durable para todos (UNMSM - UNESCO, Lima 2014)

2 Philippe Boulet Gercourt (Corresponsal en USA). "Recherche: Que mangeons nous démain? Le nouvel observateur, Paris 2 octubre 2014.

3 WWF International Rapport Planete vivant 2014. Les hommes, les especes, des espaces et des écosistemes. En colaboración con ZLS, London; GFN, USA; WFN, Países Bajos, 2014 
¿Qué modificaciones provoca esta brutal disminución de biomasa en el complejo engranaje de la reproducción natural? La polinización de los pájaros para la reproducción de plantas se reduce. Los pollos que viven de harina de pescado dispondrán potencialmente de menos recursos alimenticios. Con menos polinización habrá también menos hierbas para el pastoreo animal. La escasez de animales anfibios empobrecerá en nutrientes las aguas generando menos población de peces en lagos, ríos y costas. "Las aguas cristalinas no dan abundantes peces", recuerda un viejo proverbio chino. Este ciclo perpetuo de transustanciación molecular hace posible la reproducción de la vida animal, vegetal y humana. ¿Qué hacer ante tendencias lesivas que atentan contra la vida colectiva del mundo?

\section{Humanidad y Planeta en riesgo}

Esta inédita circunstancia del mundo debía interpelarnos a todos. Antes los cálculos no tenían la exactitud de hoy. Ahora comprobamos en carne propia que la finitud del agua, los alimentos, el oxígeno, la energía, es una realidad que nos amenaza, que la duración no es un principio abstracto y lejano. Ya Heráclito previno contra el ciclo de la muerte: Vive el Fuego de la muerte de la Tierra y vive el Aire de la del Fuego... La acción desmedida del Hombre con sus modos prometeicos de producir y consumir han desatado una enfermedad antropogénica en el planeta. En el libro colectivo Pensar un mundo durable para todos expresamos la "urgencia de reflexionar sobre la posición de América en este nuevo contexto planetario, el deber del filósofo de pensar una ciudadanía comprometida con el planeta en un mundo durable para todos". ${ }^{4}$

A este fin, la visión del filósofo Edgar Morin exponente mayor del pensamiento complejo resultó crucial, al argumentar que la construcción colectiva de una Tierra Patria en tanto "comunidad de destino planetario" demandaba una conciencia terrenal activa, conformada por una conciencia antropológica (reconocer nuestra unidad en nuestra diversidad humana); conciencia ecológica ( de los lazos consustanciales que nos unen con todos los seres vivientes en una misma biosfera); conciencia civica terrenal (de responsabilidad y solidaridad entre todos los hijos e hijas de la Tierra): Conciencia espiritual (practicar un pensamiento complejo para criticarnos y comprendernos mejor entre sí).

Esta realidad planetaria demanda un viraje hacia una nueva moral, nuevas costumbres colectivas. Las ciencias confirman que el universo es una entidad

4 Edgar Montiel, director, Pensar un mundo durable para todos, UNESCO, Universidad Mayor de San Marcos, Lima 2014. Con contribuciones de Edgar Morin, Enrique Dussel, Hugo Biagini, Ana de Miguel, Raúl Fornet Betancourt, Alejandro Serrano Calderas, Pedro Reygadas, entre otros. El libro se puede encontrar en www.cecies.com 
viviente, actuante, donde todos los seres y los sucesos están vinculados, interrelacionados en un movimiento perpetuo. Para la antigua moral estoica, aquella de Zenón y Séneca, vivir conforme a la naturaleza significaba incorporarse a un orden necesario, ya determinado 5 . La adhesión a un orden natural es distinta en la cosmología actual del universo. Hemos avanzado en el conocimiento del cosmos. Ahora se trata de dotar de una conciencia ecológica al ciudadano del mundo para que vea y sienta los vínculos consustanciales que existen entre todos los seres humanos, y entre éstos y el resto de entidades de la naturaleza: los animales, las plantas, los minerales (todos estamos hechos de las mismas materias). Y fortalecer su identidad terrenal, para que, conscientes de la reciprocidad planetaria, podamos actuar cooperativamente en defensa de los bienes comunes universales, comenzando por el principal e ineludible, la Biósfera, madre protectora, heredada del largo tiempo por miles y miles de generaciones fundantes, que ahora tenemos la responsabilidad de trasmitir a las que llegan.

El género humano, única especie inteligente, razonante, tiene el deber moral (práctico) de proteger y defender el planeta, en nombre de todas las entidades vivientes. Se trata de un deber moral y de inteligencia, análoga a la que estableció el derecho positivo, cuando sanciona al Estado o al ciudadano en caso de "no asistencia a persona en peligro". Este principio sirve a las leyes actuales que protegen a los animales en tanto "seres sensibles", parte del universo vivo.

Esta acción colectiva no deberá limitarse a lo local y nacional, sino que debe inscribirse en una dinámica mundial de defensa de la Vida en todas sus manifestaciones y de los bienes comunes universales, ese es el sentido de construir una Ciudadanía planetaria, expresión de una nueva conciencia planetaria. El concepto de Bien Común es muy antiguo, para los teólogos y filósofos de principios de la era cristiana éstos eran los bienes que un Dios Creador nos legó a todos como habitantes de la Casa Común, no para posesión privada de particulares. Bienes como los ríos y los mares (con sus aguas y sus peces), las tierras (con sus frutos y sus animales), la energía, el aire, las montañas, los cielos, el espacio, la luna, el sol etc. Pero también bienes comunes intangibles, como el amor, la honra, el respeto filial, las costumbres, la lengua, el saber, la cultura, la sabiduría etc. En el pasado, Confucio, Heráclito y Buda compartieron esta visión.

En la Edad Media esos bienes comunes fueron incorporados al Derecho Natural y al Derecho de Gentes. Para dar plena validez a estos principios y conver-

5 Seneca Lettres á Lucilius. Flammarion, Paris 1977.

6 Sobre los principios de protección al animal puede verse Sans offenser le genre humain. Réflexion sur la cause animale, de Elizabeth de Fontenoy, Albin Michel, Paris 2008; y Les droits de l'animal de Jean Marie Coulon y Jean Claude Nouet, Editions Dalloz, Paris 2009. 
tirlos en Derecho positivo no mera tradición se realizaron las movilizaciones ciudadanas de la Era Moderna por los Derechos Humanos, la Soberanía popular, la Independencia de los pueblos. Grandes figuras de la Humanidad defendieron estas causas, como Vitoria, Las Casas, Inca Garcilaso, Grotius ${ }^{7}$, Jean Bodin, Pufendort, Hobbes, Locke, Vattel, Jefferson, Rousseau, Voltaire, Kant, entre otros. Hoy, en situación de urgencia, el Papa Francisco exhorta a la Humanidad a "tomar conciencia de la necesidad de cambiar de estilo de vida, de producción y de consumo", como bien resume la Encíclica Alabado seas.

\section{Educar la ciudadanía mundial a bien vivir}

Junto a los grandes consorcios industriales, hoy en día la oligarquía financiera mundial y las megaestructuras tecnológicas, se interesan en particular por el patrimonio común de la humanidad: el agua (incluyendo las lluvias), el aire (y la energía que generan), los conocimientos-saberes-culturas-ciencias (vía patentes), el mar con sus peces, los metales, la energía fósil, las tierras comunitarias, el espacio (incluido el ciberespacio), el espacio aéreo, el espectro de telecomunicaciones, y ahora se ha desatado una carrera por la apropiación de los recursos de la Luna y de Marte. Se acelera el proceso de privatización del patrimonio colectivo y su concentración en manos de megaconsorcios. Hemos entrado en la era del cosmo-capitalismo y el capitalismo numérico, que atañe, además, a las libertades públicas. ${ }^{8}$

A un reto de esta magnitud debe responder otro semejante, desde el lado de la ciudadanía mundial, de los derechos humanos de todos los pueblos, en defensa de un planeta durable para todos, en base a un Derecho Cosmo-político. Kant sostuvo aleccionado por el ejemplo de la Constitución de las colonias inglesas como Estados Unidos de América que el comercio era un factor de paz, entendimiento y prosperidad entre las naciones. Y no le faltó razón. Es cuando escribe que "El derecho de ciudadanía mundial debe asentarse en las condiciones de una universal hospitalidad...Fúndase este derecho en la común posesión de la superficie de la tierra"'. Estas luces abonaron el movimiento por la Independencias de las Naciones y las Revoluciones por los Derechos Humanos. Con estas ideas precursoras se fundaron las Naciones Unidas.

Hoy en día la lógica del mercado ciego nos lleva a la ruptura de las armonías esenciales entre la Sociedad, la Economía y la Naturaleza. Grave problema para

\footnotetext{
7 Hugo Grotius, con su célebre tratado El derecho de la guerra y de la paz (1625) ha reunido el más completo volumen que estudia los principios del Derecho Natural y del Derecho de Gentes, otorgándoles un estatuto jurídico pleno, según los cánones de la era Moderna.

8 Pierre Dardot, Christian Laval. Commun. Essai sur la révolution au XXI siecle. La Découverte, Paris 2014.

9 Immanuel Kant, Sobre la Paz Perpetua, Biblioteca Virtual Miguel de Cervantes Saavedra.
} 
el consumo humano, la economía sostenible, y las Instituciones, incluyendo las Naciones Unidas. La ONU acordó darse Objetivos de Desarrollo Sostenibles para el 2030 (ODS), es decir logros duraderos en la reducción de la pobreza y la exclusión, atenuar el recalentamiento climático protegiendo las aguas y las energías, e impartir una educación ciudadana para la equidad, el consumo responsable y la vida sana. Pero, ¿Que puede hacer el ciudadano de a pie, la familia, la escuela, la universidad, las iglesias, las asociaciones, por ese planeta durable y para todos?

Es mucho lo que se puede hacer en lo individual. Comenzando por tener una educación para el consumo. Atrapados por un consumismo compulsivo, somos el blanco de una oferta mundial de gran escala, una oferta caudalosa para convencer al cliente con una doble presión, la del arsenal publicitario y la presión social que el propio consumismo genera (el efecto "bola de nieve" buscado). El mercado ha incorporado a su oferta a todos los grupos etarios como consumidores a explotar, comenzando con su oferta para bebes, "adultiza" también el consumo de niños y niñas con ropas y zapatos y artefactos electrónicos, inflando sus demandas; los adolescentes son otro grupo etario voraz, altamente consumidor en ropas, zapatos, comidas, celulares, computadoras, cámaras, ¡último modelo por supuesto ${ }_{i}$ Adultos y adultos mayores son otro target favoritos por su poder adquisitivo. Las modas ritman el consumo de todos los géneros y edades. Ya no hay territorios en el mundo fuera del mercado. El mercado unifica y manda, e impone una moral simple: todo se vende y todo se compra. Todo tiene un precio. Es el valor que predomina sobre los otros.

Este modo de producir y consumir tiene insumos de alto impacto ambiental. Al que se suma la drástica reducción de "vida útil" de los productos. Antes una lavadora, un refrigerador, un auto, duraba al menos una década. Hoy el ciclo de innovación es permanente, se cambian modelos para aumentar el lucro. Esta manera de producir iniciado hace 60 ańos con las cámaras de foto y filmadoras se ha generalizado, ahora la innovación perpetua es obligatoria para ser competitivo en el mercado. Esta rápida rotación de artefactos genera millones de toneladas de basura, subiendo la contaminación ambiental (en el siglo XX este modo de producción subió en 1 grado el recalentamiento histórico). Hay países pobres que reciben desechos. Prolifera en el mundo una lógica productiva basada en lo ligero, frágil y desechable: hay exceso de empaquetado de aparatos como en la comida congelada, se reduce las dosis de componentes curativos en medicamentos. Los costos se reducen y se suben los precios de venta. No hay regulación sobre esto, el Estado protege poco al consumidor. Las fuerzas ciegas mandan.

Esta lógica es contraria al principio planeta durable, este vivir para consumir, este culto de lo efímero, lo aparencial, de adoración de las cosas, que de tanto 
poseer dejan el gobierno de sus vidas a las cosas. Esta cosificación olvida que las personas, la comunidad, tienen una dignidad no un precio. Que hay valores de reciprocidad, de cooperación, de solidaridad individual y colectiva.

Este apetito voraz por poseer bienes materiales la pleonexia ha sido tipificado por Platón como una enfermedad hace dos mil 500 ańos. Fue considerado siempre un antivalor, pero ha cambiado de signo en las últimas décadas con las teorías monetaristas de Milton Friedman y su escuela, que estiman el triunfo personal por los "cantidad de cosas" que se tiene.

En estas circunstancias, se requiere una consciencia crítica despierta para salir del axioma ¡Compro, luego existo! ¡ Tengo, luego soy!; necesitamos reeducar nuestras vidas, aprender nuevos hábitos de consumo que vayan en sentido de la reproducción sostenible de la vida, convencidos que la realización humana está más en el ser que en el tener. A esto ayudará mucho una Educación práctica de vida sostenible como proponen la UNESCO y los ODS al promover un consumo sano, diversificado, alternativo. A eso servirá una Ciencia preocupada por la ecología, como la experiencia de producción de carnes y huevos en laboratorios, jsabroso y sin colesterol $i$ ni efectos invernaderos, así como la ampliación del menú habitual gracias a las comidas de culturas distintas. En el campo de la salud podría ocurrir lo mismo, una ampliación de los métodos curativos naturales, sapienciales; todo esto ayudará al entendimiento entre los pueblos, a fortalecer los vínculos sociales y la construcción empatías, un buen vivir juntos.

El reto es grande y apremiante, mantener encendida la luz de la cultura crítica, la educación para el consumo y la alteridad, un saber abierto a todas las tradiciones de pensamiento. Esa luz del conocimiento que debe llegar al comprador o al elector, a los niños y niñas, a los jóvenes.

Vivimos en una sociedad del espectáculo, en la era de la imagen ${ }^{10}$, donde todo lo que toca una cámara se vuelve diversión: una guerra en directo, un tsunami, una feria de autos o un acto terrorista. El videotismo futbolístico es el mejor mal ejemplo. Necesitamos reeducar nuestra mirada, avivar nuestra razón crítica, sumar nuestros actos a la resistencia cotidiana contra la degradación de nuestro mundo. Convendría hoy emular el bienestar estoico: una existencia frugal, vida sobria, sentido de fraternidad, probos en política y serenos en la adversidad, y aspirar siempre a una vida larga, durable...

París/Lima, 2014

10 Edgar Montiel, El poder de la cultura. Recurso estratégico del desarrollo durable y la gobernanza democrática. FCE, Lima 2010. 